\title{
Promoting analysis of real-world data: Prospects for preventive cardiology in Japan
}

\author{
Haruki Yotsumoto ${ }^{1}$, Hidehiro Kaneko ${ }^{1,2, *}$, Hidetaka Itoh ${ }^{1}$, Tatsuya Kamon ${ }^{1}$, Hiroyuki Kiriyama ${ }^{1}$, Katsuhito Fujiu ${ }^{1,2}$, \\ Norifumi Takeda ${ }^{1}$, Hiroyuki Morita ${ }^{1}$, Issei Komuro ${ }^{1}$ \\ ${ }^{1}$ Department of Cardiovascular Medicine, The University of Tokyo, Tokyo, Japan; \\ ${ }^{2}$ Department of Advanced Cardiology, The University of Tokyo, Tokyo, Japan.
}

\begin{abstract}
According to the statistics for 2018 in Japan, cardiovascular disease and cerebrovascular disease were the most common causes of death (cardiovascular disease with 208,210, cerebrovascular disease with 108,165), and these two diseases account for $23.2 \%$ of all deaths. Stroke, especially cerebral hemorrhage, was the main cause of death in Japan after World War II. Along with improved management of hypertension, the mortality rate from cerebral hemorrhage reached a high of 266.7 per 100,000 men in 1960 and 213.9 per 100,000 women in 1951, then decreased to 15.9 per 100,000 men and 6.9 per 100,000 women in 2013 . However, mortality from lifestylerelated diseases such as metabolic syndrome and ischemic heart disease has been on the rise since 1990 due to the westernization of diet, urban lifestyles, and lack of exercise habits. Moreover, since aging is the greatest risk factor for heart failure, the number of patients with heart failure in Japan will inevitably increase in the future. A large amount of evidence has demonstrated that prevention and proper management of risk factors can reduce the future incidence of cardiovascular disease. Specific health checkups (metabolic syndrome checkups) have been carried out in Japan since 2008. Big data on physical examinations are valuable real-world data that can be utilized for clinical research. As the importance of preventive cardiology increases in the future, we should analyze the real-world data from health checkups in Japan in detail and disseminate these results to clinical practice, which will contribute to development of preventive cardiology and the promotion of public health.
\end{abstract}

Keywords: preventive medicine, cardiovascular disease, modifiable risk factors, health checkup

\section{Introduction}

In January 2020, the Cabinet Office announced the "Moonshot Goals" (1). The Moonshot Goals define six specific challenges that are difficult, but which, if realized, will have a significant impact on society. One of them is to "create a society in which it is possible to predict and prevent disease at an extremely early stage by $2050 "$. Preventive medicine is now a national project of great importance in Japan.

The purpose of this review is to overview the efforts of preventive medicine in cardiovascular diseases (CVD). We will consider the importance of CVD in the medical care of Japan and the efforts of preventive cardiology in comparison with the situation in other countries.

\section{The place of cardiovascular disease in the history of} medicine

The most recent causes of deaths in Japan (statistics for 2018) were as follows: malignant neoplasms (tumors) with 373,547 , CVD with 208,210 , senility with
109,606, and cerebrovascular disease with 108,165 . CVD and cerebrovascular disease account for $23.2 \%$ of all deaths (2).

According to the United States statistics for 2018, the leading causes of the 2,813,503 deaths per year in the United States are heart disease $(647,457)$, malignant neoplasms $(599,108)$, accidents $(169,936)$, chronic respiratory diseases $(160,201)$, and strokes $(146,383)$. CVD account for $28.2 \%$ of all deaths, including heart disease and stroke (3). Conquering CVD is a challenge not only for Japan, but for most developed countries.

The place of CVD in the history of medicine has largely changed. Today, the novel coronavirus infection (COVID-19) is rampant throughout the world. Since the dawn of history, infectious diseases have been the greatest threat to humanity. The Black Death in the $14^{\text {th }}$ and $16^{\text {th }}$ centuries and the Spanish flu in the early $20^{\text {th }}$ century are the most notable examples of infectious disease pandemics. In Japan, tuberculosis was the leading cause of death in the early 20th century (the death rate from tuberculosis in 1918 was 257.1 per 100,000 people, far higher than that of malignant neoplasms (4)). On the 
other hand, prevention of infectious diseases was greatly promoted by improved sanitary conditions and the development of vaccines or antibiotics. The Tuberculosis Prevention Act was enacted in 1951, and the prevalence of streptomycin and other antimicrobial treatments has dramatically reduced the mortality rate due to tuberculosis in Japan.

While deaths from tuberculosis have decreased dramatically, stroke, particularly cerebral hemorrhage, was the main cause of death in Japan after World War II. The high salt content of the Japanese diet originally caused a high prevalence of hypertension, and the lack of proper control of hypertension is thought to have increased the number of deaths from cerebral hemorrhage. A national campaign to reduce salt intake was launched, and the Labor Standards Law required employers to provide workers with medical examinations in 1947, and the amendments to the National Health Insurance Law made antihypertensive treatment more widespread in 1961, which improved the management of hypertension. Along with improved management of hypertension, the mortality rate from stroke (cerebral hemorrhage) has dramatically decreased (Figure 1). The mortality rate from cerebral hemorrhage reached a high of 266.7 per 100,000 men in 1960 and 213.9 per 100,000 women in 1951 , then decreased to 15.9 per 100,000 men and 6.9 per 100,000 women in 2013 (5). In 1972, the Occupational Health and Safety Law was enacted, and in addition to the tuberculosisrelated health checkup items that had been included in the Labor Standards Law, items such as blood pressure measurement were added to the health checkup. Since then, items aimed at health management other than countermeasures against infectious diseases have been added, and these items are now part of regular health checkups. Under the Community Health Law, health centers have been established throughout the country to provide health checkups for local residents (6).

While deaths from cerebral hemorrhage have decreased, mortality from lifestyle-related diseases such as metabolic syndrome and ischemic heart disease has been on the rise since 1990 due to unhealthy lifestyles including the westernization of diet, urban lifestyles, and physical inactivity (Figure 2). To reduce the burden of ischemic heart disease, it is important to prevent these lifestyle-related diseases that are increasing in middle-aged adults.

In 2008, the Ministry of Health, Labour and Welfare (MHLW) started the Specific Health Examination (commonly known as "metabolic syndrome health examination") (7) for adults between the ages of 40 and 74. The Specific Health Examination is a rare initiative in the world that aims for early detection of lifestyle-related diseases such as metabolic syndrome and the prevention of CVD on a nationwide scale. Ten years have already passed since the Specific Health Examination began, and it is now time to review the effectiveness of the Specific Health Examination and devise more effective ways to conduct health examinations.

Heart failure is one of the most important CVD that will become increasingly important in the future. The number of patients with heart failure has been increasing rapidly in Japan due to the rapid aging of society and the increase in the number of young and middle-aged people with ischemic heart disease. The number of patients with heart failure is estimated to continue to rise, reaching 1.3 million by 2030 in Japan (8).

The epidemiological situation of an increasing number of patients with heart failure is called "heart failure pandemic", which is a common problem not only in Japan but also in other developed countries with aging populations. In 2015 , the proportion of the elderly

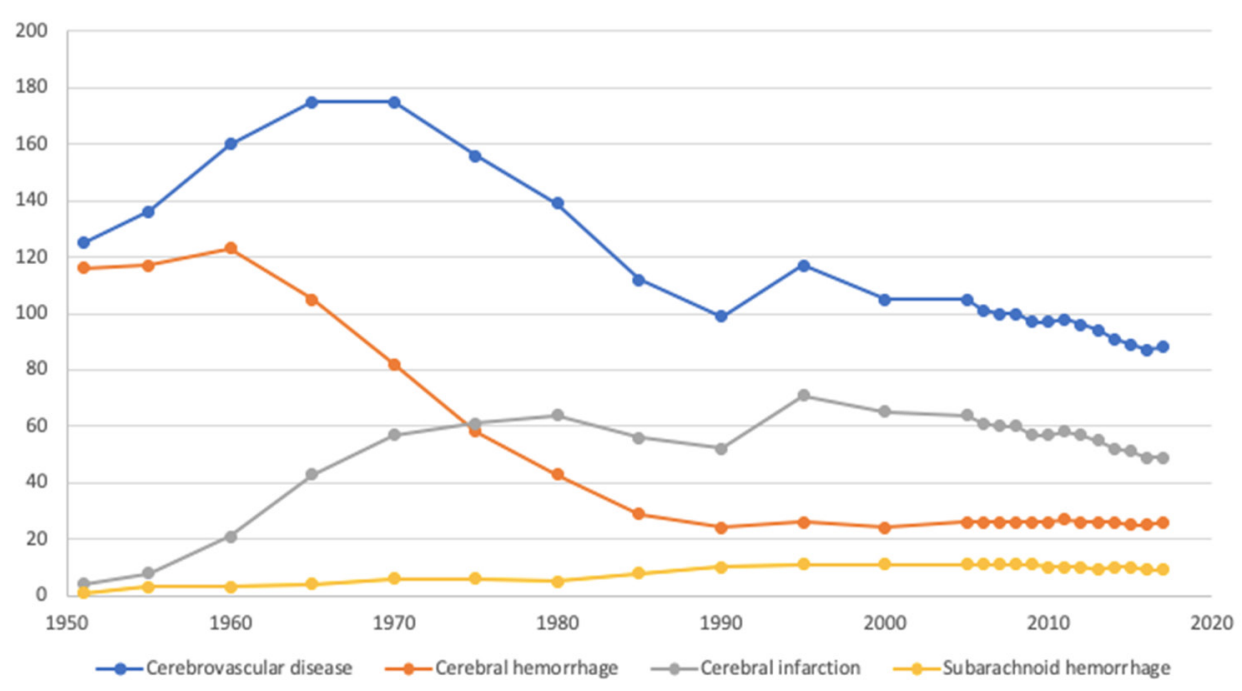

Figure 1. Trends in mortality by stroke category in Japan (per 100,000). Data Source: (5). 


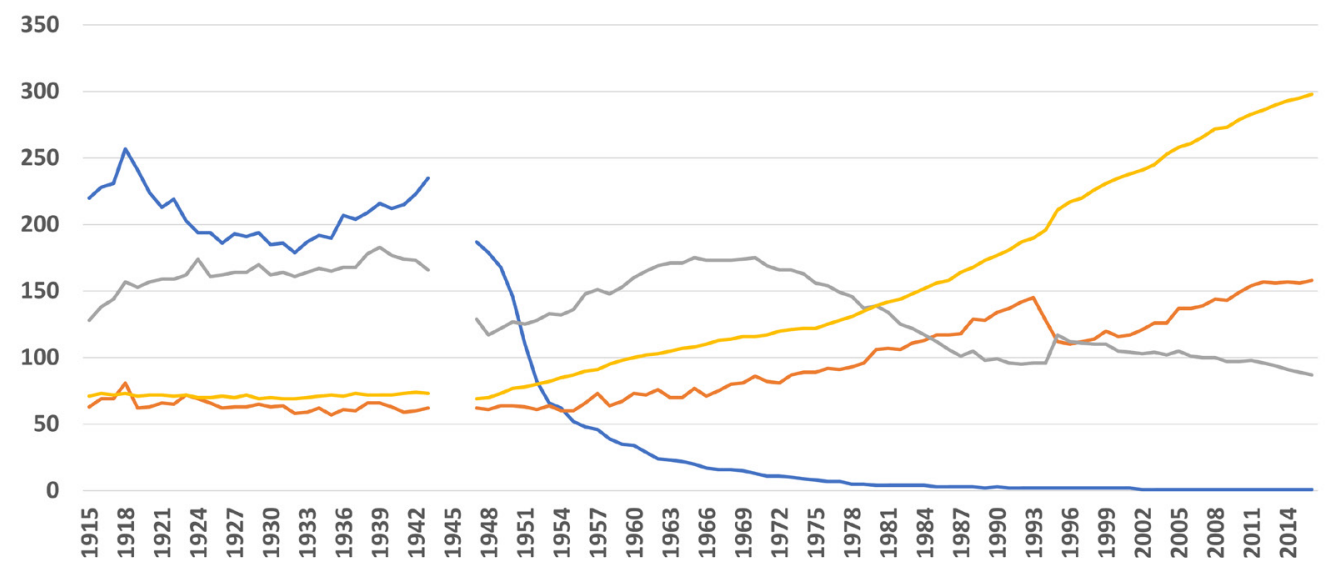

Figure 2. Mortality rate by disease (per 100,000). Blue: tuberculosis; gray: cerebrovascular disease; orange: ischemic heart disease; yellow: malignant neoplasm. Data Source: (4).

in Japan (the percentage of the population aged 65 and over) was $26.6 \%$, which is higher compared to $14.6 \%$ in the United States, $21.1 \%$ in Germany, and $9.7 \%$ in China (9). Japan is one of the countries with the most aged population in the world. Japan is aging rapidly: in 1960, Japan's aging rate was $5.7 \%$, whereas in 2010 it reached $23.0 \%$ (Figure S1, https://www.globalhealthmedicine. com/site/supplementaldata.html?ID=27). In 2018, for a population of 126.43 million, there were 35.56 million (28.1\%) people aged 65 years and older, and 17.95 million (14.2\%) people in the later stages of 75 years and older. Declining birthrate as well as aging population in Japan is a difficult problem to solve, and the percentage of aged population is expected to continue to increase in the future, with the Cabinet Office estimating that by 2065 , approximately 1 in 2.6 Japanese will be 65 years of age or older, and 1 in 3.9 will be 75 years of age or older (10). Because aging is the greatest risk factor for heart failure, the number of patients with heart failure in Japan will inevitably increase in the future. In our study, more than $50 \%$ of heart failure patients were aged 80 years or older, and the number of very old people aged 90 years or older was close to $20 \%$ of heart failure patients (11). As an advanced aging society, Japan's efforts to address the heart failure pandemic at the national level are getting attention from countries around the world.

\section{Three reasons why prevention is important in cardiovascular disease}

\section{Effect on healthy life expectancy}

Although Japan is known as one of the countries with the longest life expectancy in the world, there is a gap of about 10 years between healthy life expectancy and actual life expectancy (about 9 years for men and 12 years for women (12)). This gap is a period of time during which patients are limited in their daily lives due to health problems, such as the need for support and care, which not only degrades the quality of life of the individual patient, but also places a heavy burden on the family to support the patient, which cannot be overlooked in terms of social productivity. The fact that CVD, including stroke and heart failure, are major causes of reduced healthy life expectancy (13-15) as well as reduced life expectancy, is one of the major reasons why it is important to prevent CVD.

\section{Impact on medical costs}

The cost of medical care in Japan has continued to increase: from 16.0 trillion yen (160 billion dollars) in 1985 to 30.1 trillion yen (301 billion dollars) in 2000 and 42.3 trillion yen (423 billion dollars) in 2015 (Figure S2, https://www.globalhealthmedicine.com/site/ supplementaldata.html?ID=27). The share of medical costs for the elderly in the later stages of life has also increased as a percentage of national medical costs, rising from $25.4 \%$ in 1985 to $35.9 \%$ in 2015 (16). CVD are a significant burden on medical costs, with medical care costs for CVD of 5.9 trillion yen (59 billion dollars), which accounted for the highest percentage (19.9\%), followed by "Malignant neoplasms" at 4,125.7 billion yen (41.2 billion dollars) (13.7\%), "Musculoskeletal and connective tissue diseases" at 2,326.1 billion yen (23.2 billion dollars) (7.7\%), "Respiratory diseases" at 2,223.0 billion yen (22.2 billion dollars) (7.4\%), and "Injury, poisoning and other external causes" at 221.2 billion yen (2.2 billion dollars) (7.4\%) (17). By age group, malignant neoplasms accounted for 1,521.2 billion yen (15.2 billion dollars) (13.0\% of the total) more than CVD among those under 65 years of age, but CVD accounted for 4,686.9 billion yen (46.9 billion dollars) (25.5\%) more than malignant neoplasms among those 65 years of age and older. Considering that Japan's population will be aging further in the future, prevention of CVD is extremely important from a health care economic standpoint. 


\section{Prevention is effective for cardiovascular disease}

Many epidemiological studies have identified a variety of risk factors for CVD. As discussed in more detail below, many of the risk factors for CVD are modifiable risk factors that can be ameliorated by lifestyle modifications and pharmacological intervention, and a large body of evidence demonstrates that proper management of these modifiable risk factors can reduce the future incidence of CVD (18-20). In Japan, a major objective of widespread health screening is to detect these risk factors early. The major goal of widespread health screening in Japan is the early detection of these risk factors and early intervention to prevent the development of CVD. It should be emphasized that, compared with malignancies, degenerative diseases, and genetic disorders, modifying risk factors is more effective for the prevention of most CVD.

\section{Epidemiological studies identifying risk factors for cardiovascular disease}

Many epidemiological studies have been conducted in Japan and abroad to clarify risk factors for CVD. Representative epidemiological studies are described below.

\section{Framingham study}

The Framingham study (21), the first large-scale epidemiological study of CVD, was initiated in 1948 by the National Institutes of Health in Framingham, Massachusetts, USA. At the time, the increase in CVD was an epidemiologic problem in the United States, but little was known about risk factors of CVD. The Framingham study, which began with 5,209 adult residents between the ages of 30 and 62 , is an historic study that is now on its third generation of participants. The Framingham study revealed risk factors for CVD, including obesity, hypertension, hypercholesterolemia, diabetes mellitus, smoking, and physical inactivity (22), which have shaped today's cardiovascular practice. Framingham Risk Score, which is widely used in the CVD prediction, was published in 1998. Framingham Risk Score predicts incidence of ischemic heart disease within 10 years based on the sum of age, gender, total cholesterol, high-density lipoprotein (HDL) cholesterol, systolic blood pressure, blood pressure medication, and smoking status (23).

\section{Hisayama study}

Since 1961, the Department of Public Health of Kyushu University has been leading a prospective follow-up study of CVD which mainly focused on stroke among the residents of Hisayama-cho (population 8,400), which is adjacent to Fukuoka City (24). Residents of
Hisayama have about the same age and occupational distribution as the national average, and they represent an average Japanese population with little or no bias. The study was prompted by the fact that, at the time, deaths from cerebral hemorrhage were 12.4 times higher than those from cerebral infarction in Japan, which was significantly higher than in Europe and the United States, and there were inquiries from European and American researchers that the predominance of cerebral hemorrhage may have been due to a misdiagnosis. There was no data to verify this, so the Hisayama study was initiated to clarify the reality of stroke in Japan. Early data of Hisayama study showed that the mortality rate from cerebral hemorrhage was 1.1 times that of cerebral infarction, which was inconsistent with the Japanese report at that time, which stated that the mortality rate from cerebral hemorrhage was 12.4 times that of cerebral infarction. Therefore, it is possible that some of the cases diagnosed as cerebral hemorrhage should have been diagnosed as cerebral infarction. A unique feature of the Hisayama study is the high autopsy rate of $75 \%$. Autopsies are indispensable in determining the exact cause of death. The follow-up rate is also high (99\%), and a new cohort of residents aged 40 years or older is added to the study every 5 years, providing insight into changes in lifestyle and prevalence of risk factors.

Although there is an amount of knowledge that has been revealed by the Hisayama study, we highlight two of them here. First, high diurnal variation in home blood pressure was found to be a risk for development of dementia (25). Although observational studies had previously shown that high variation in blood pressure per reception was indicative of cognitive decline, none had evaluated home blood pressure. This study suggested that home blood pressure variability and hypertension were associated with the development of vascular dementia (25), whereas home blood pressure variability (independent of hypertension) was a risk for Alzheimer's disease (26). In another study, airflow limitation was found to be a significant risk factor for carotid atherosclerosis, especially in middle age (27). This is the first study to show a relationship between chronic obstructive pulmonary disease with airflow limitation and carotid atherosclerosis in a large group of the Asian population (27).

\section{Suita study}

This cohort study began in 1989. Of 12,200 men and women randomly selected from the basic resident register in Suita, Osaka Prefecture, 6,485 people aged 30-79 years old who underwent an initial health examination were included in the study (28). After the initial health check-up, the participants undergo regular check-ups every two years at the National Cerebral and Cardiovascular Center. The survey is conducted annually 
by mail or telephone. The Suita Cardiovascular Disease Score, which predicts the probability of developing coronary artery disease and stroke within 10 years, was developed based on data tracking the incidence of coronary artery disease and stroke through December 2013 (29).

The risk of myocardial infarction in the Japanese population is enormously lower than that in Westerners. A comparison of the diagnostic performance of the Framingham Risk Score, a score used in Europe and the United States and the Suita score showed that the Framingham Risk Score tended to overestimate the probability of developing coronary artery disease (up to $14 \%$ ), whereas the Suita score almost accurately predicted the probability of developing coronary artery disease (30). The Suita score is expected to be useful in predicting cardiovascular events in the general population living in an urban setting.

\section{Modifiable risk factors in cardiovascular disease}

\section{Obesity and metabolic syndrome}

Medical problems from a nutritional perspective have shifted from being caused by malnutrition to overnutrition in the immediate aftermath of World War II. The diet of the Japanese people changed dramatically between 1950 and 1975, with intake of meat, poultry and eggs increasing 7.5-fold, fat intake increasing 6-fold, and milk intake increasing 15-fold (31). Westernization of dietary habits and overnutrition led to a noticeable increase in obese subjects. As shown in the Figure, the average BMI has increased, especially among men (Figure 3A), and the proportion of obesity has increased accordingly. Because obesity is closely related to the development of lifestyle-related diseases and even CVD (32), early detection of overweight and obesity through health checkups and other measures, including nutritional and exercise guidance, are necessary to maintain an appropriate body weight.

The diagnostic criteria for metabolic syndrome in Japan include $i$ ) Waist circumference of $\geq 85 \mathrm{~cm}$ for men and $\geq 90 \mathrm{~cm}$ for women; ii) Two or more of the following items must be met: (a) triglycerides $\geq 150$ $\mathrm{mg} / \mathrm{dL}$, or HDL $<40 \mathrm{mg} / \mathrm{dL}$, (b) systolic blood pressure of $\geq 130 \mathrm{mmHg}$ or diastolic blood pressure of $\geq 85$ $\mathrm{mmHg}$, (c) fasting blood glucose of $\geq 110 \mathrm{mg} / \mathrm{dL}$ (33).

Obesity, abdominal obesity (high waist circumference), and metabolic syndrome often coexist. On the other hand, the term "metabolically healthy obesity" has been used to describe a condition that is obese but not associated with metabolic disorders or the metabolic syndrome, and it has received much attention $(34,35)$. There are two definitions of obesity by itself, one with a cutoff of BMI $30 \mathrm{~kg} / \mathrm{m}^{2}$ and the other with a cutoff of BMI $25 \mathrm{~kg} / \mathrm{m}^{2}$. Furthermore, metabolically healthy obesity is often defined as a condition in which "obesity is present but no metabolic abnormalities are present at all," and is sometimes defined as "being obese but not meeting the definition of metabolic syndrome." The fact that the definition of metabolic syndrome differs from country to country is another reason for the confusion in the definition of metabolically healthy obesity. In addition, there are cases of metabolic syndrome that shift from metabolically healthy obesity to metabolically unhealthy obesity over time, and more detailed studies in this area will help to establish the definition and understand the optimal management for "metabolically healthy obesity".

\section{Hypertension}

Although it is important to exclude secondary hypertension, such as primary hyperaldosteronism, from hypertensive cases, many of the cases have socalled "essential" hypertension, which is caused by a combination of environmental and genetic factors that contribute to the predisposition to hypertension. Epidemiological studies in Japan have shown a correlation between average salt intake and the prevalence of hypertension in the region. Epidemiological studies have also shown that dietary treatment, such as salt restriction, is effective in lowering blood pressure. Conventional Japanese diets contain too much salt, which increases the prevalence of hypertension and contributes to the incidence of stroke. As mentioned above, national-scale interventions in salt intake restriction and hypertension management began around 1960, and the daily salt intake of Japanese people was about $15 \mathrm{~g}$ in the 1950s, but in the 2010s it was less than $10 \mathrm{~g}$ (Figure 3B) (36). Salt reduction is important not only for the prevention of hypertension, but also for the prevention of heart failure and chronic renal failure, and we should continue efforts to reduce salt intake.

A current topic in hypertension is the diagnostic criteria for hypertension: the ACC/AHA blood pressure guidelines published in 2017 lowered the value of blood pressure in the diagnostic criteria for hypertension from $140 \mathrm{mmHg}$ of systolic blood pressure and $90 \mathrm{mmHg}$ of diastolic blood pressure to $130 \mathrm{mmHg}$ of systolic blood pressure and $80 \mathrm{mmHg}$ of diastolic blood pressure (37). On the other hand, the European guidelines remained the previous definition of hypertension and defined hypertension as systolic blood pressure $\geq 140 \mathrm{mmHg}$ or diastolic blood pressure $\geq 90 \mathrm{mmHg}$ (38). Similarly, the Japanese guidelines published in 2019 did not change the criteria for hypertension, and therefore, the diagnostic value for hypertension is the systolic blood pressure of $140 \mathrm{mmHg}$ or the diastolic blood pressure of $90 \mathrm{mmHg}$ (39). On the other hand, as the SPRINT study (40) showed, strict antihypertensive treatment has proven to be effective in reducing cardiovascular events. In addition, large registry studies 

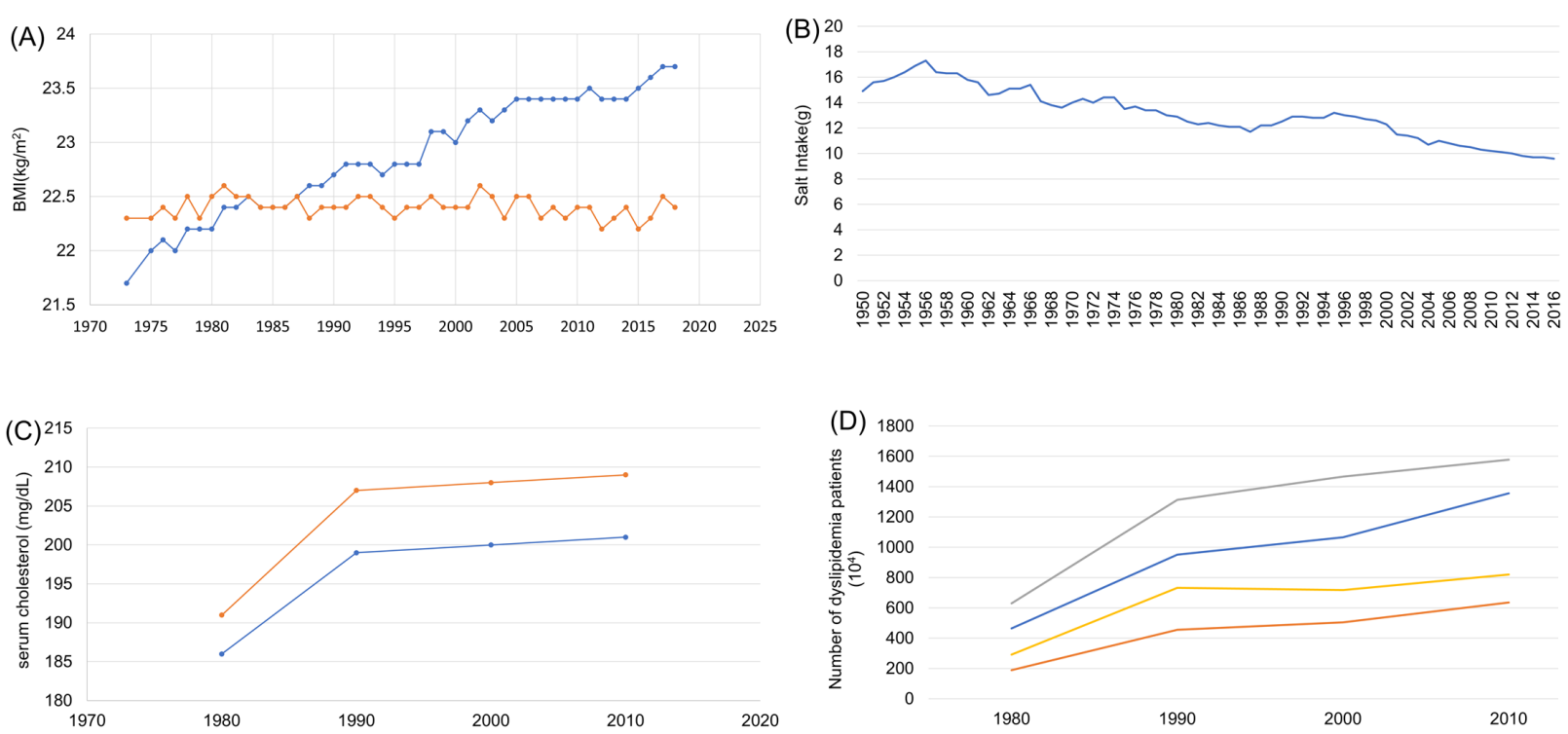

Figure 3. Trends in modifiable risk factors of cardiovascular disease among Japanese. (A) Trends in BMI. Blue: male; Orange: female. (B) Trends in salt intake. (C) Trends in serum cholesterol levels (mg/dL). Blue: male; Orange: female. (D) Prevalence of dyslipidemia, age 30 years and older. Blue: $>220 \mathrm{mg} / \mathrm{dL}$ (male); orange: $>240 \mathrm{mg} / \mathrm{dL}$ (male); gray: > $220 \mathrm{mg} / \mathrm{dL}$ (female); yellow: > $240 \mathrm{mg} / \mathrm{dL}$ (female). Data Source: (https://www.nibiohn.go.jp/eiken/kenkounippon21/eiyouchousa/keinen_ henka_shintai.html $(36,44))$.

in the United States and South Korea have shown that blood pressure classifications based on the $2017 \mathrm{ACC} /$ AHA blood pressure guidelines are effective for risk stratification of cardiovascular events in young adults $(41,42)$. Furthermore, the analysis of a populationdatabase in Japan also showed that compared with normal blood pressure, both stage 1 hypertension and stage 2 hypertension according to the 2017 ACC/AHA blood pressure guidelines were associated with an elevated risk of heart failure and atrial fibrillation (43). We need further data to establish the cut-off value of blood pressure for the diagnosis of hypertension and to determine the optimal target value of blood pressure for the prevention of CVD.

\section{Hypercholesterolemia (Dyslipidemia)}

The prevalence of hypercholesterolemia and dyslipidemia in the Japanese population has changed significantly due to the westernization of diet in the Japanese people. The earliest report on lipid levels in official statistics is the Third Cardiovascular Disease Survey, conducted in 1980 (44). The Cardiovascular Disease Survey is conducted every 10 years, and it reports the change in lipid levels for the 30 years from 1980 to 2010 . The increase in serum cholesterol levels between 1980 and 1990 for both men and women was greater than in the latter two decades, from $186 \mathrm{mg} / \mathrm{dL}$ in 1980 to $199 \mathrm{mg} / \mathrm{dL}$ in 1990 for men aged 30 years and older, and from $191 \mathrm{mg} / \mathrm{dL}$ to $207 \mathrm{mg} / \mathrm{dL}$ for women aged 30 years and older, with an increase of $13-16 \mathrm{mg} / \mathrm{dL}$ in 10 years, respectively
(Figure 3C). The prevalence of dyslipidemia in people aged 30 years and older changed from 1980 to 2010 in the Cardiovascular Disease Basic Survey and the National Health and Nutrition Survey (Figure 3D). These results were estimated from the prevalence of hypercholesterolemia based on the census population and total cholesterol levels in each year. The criteria for hypercholesterolemia which have long been used in Japan and the United States are as follows: $220 \mathrm{mg} /$ $\mathrm{dL}$ or higher in Japan and $240 \mathrm{mg} / \mathrm{dL}$ or higher in the United States (44).

In addition, according to a 2017 survey by the Ministry of Health, Labour and Welfare on the proportion of people with suspected dyslipidemia according to age and sex, the proportion of men is higher than that of women under 60 years of age, whereas the proportion of women is similar to that of men over 60 years of age (Table 1) (45).

For patients with hypercholesterolemia (dyslipidemia), it is important to first investigate the causes (e.g. familial hypercholesterolemia, hypothyroidism), as well as to provide nutritional and lifestyle guidance. We believe that early introduction of statins is the key to prevent future CVD. Statins have become an essential part of the armamentarium against CVD based on the extensive evidence both on primary prevention and secondary prevention for CVD. As shown in the Table, the lower the low-density lipoprotein cholesterol (LDL-C) levels achieved in both primary and secondary CVD prevention, the lower the incidence of cardiovascular event rate (Table 2) (46). Particularly for secondary CVD prevention, the LDL-C target of less 
Table 1. Percentage of people with suspected dyslipidemia by age and gender

\begin{tabular}{llllllll}
\hline & Total & $20-29$ & $30-39$ & $40-49$ & $50-59$ & $60-69$ & $70 \sim$ \\
\hline Total & 42.2 & 21.1 & 26.3 & 35.4 & 52.2 & 52.3 \\
Male & 47.7 & 27.0 & 44.2 & 52.8 & 56.7 & 52.6 \\
Female & 38.6 & 17.2 & 16.9 & 25.9 & 49.3 & 41.4 \\
\hline
\end{tabular}

Table 2. Relationship between LDL-C achievement and cardiovascular event rates

\begin{tabular}{|c|c|c|c|c|c|}
\hline & Trial & $\begin{array}{c}\text { Baseline LDL-C } \\
(\mathrm{mg} / \mathrm{dL})\end{array}$ & $\begin{array}{c}\text { LCL-C Achieved } \\
(\mathrm{mg} / \mathrm{dL})\end{array}$ & $\begin{array}{c}\text { Statin Event Rate } \\
(\%)\end{array}$ & $\begin{array}{c}\text { Placebo Event Rate } \\
(\%)\end{array}$ \\
\hline \multirow[t]{2}{*}{ Primary prevention } & WOSCOPS & 192 & 159 & 5.3 & 7.5 \\
\hline & AFCAPS & 150 & 115 & 3.5 & 5.5 \\
\hline \multirow[t]{3}{*}{ Secondary prevention } & $4 \mathrm{~S}$ & 188 & 122 & 19.4 & 27.9 \\
\hline & CARE & 139 & 98 & 10.2 & 13.2 \\
\hline & LIPID & 150 & 112 & 12.3 & 15.7 \\
\hline
\end{tabular}

than $70 \mathrm{mg} / \mathrm{dL}$ should be achieved. However, achieving the therapeutic target of LDL-C is sometimes difficult in real-world clinical practice. Notably, there may be cases that require the highest dose of statins, multiple drugs, or even PCSK9 inhibitors, particularly in cases of familial hypercholesterolemia.

\section{Diabetes mellitus}

It is also widely known that diabetes mellitus is associated with CVD. Although non-pharmacological treatments such as dietary counseling are the first choice for diabetes mellitus, in practice, many patients require pharmacological treatment including oral diabetic drugs or insulin. The current topic in the treatment of diabetes mellitus is the SGLT2 inhibitors, which exert their glucose-lowering effects by inhibiting glucose reuptake in the renal proximal tubules. Large clinical trials such as the ACCORD trial (47), the ADVANCE trial (48) and the VADT trial (49) have shown that strict glycemic control does not reduce cardiovascular events in type 2 diabetes mellitus. In addition, DPP4 inhibitors, which have shown positive results in animal studies, did not reduce cardiovascular events in the SAVOR-TIMI53 (50), EXAMINE (51), and TECOS studies (52). Rather, the SAVOR study showed an increase in heart failure hospitalizations in the DPP4 inhibitor group. In the EMPAREG-OUTCOME study (53) and the CANVAS study (54), SGLT2 inhibitors were shown to reduce cardiovascular events (55), and have become the focus of attention in diabetes mellitus treatment. In particular, the effect of SGLT2 inhibitors on heart failure events is an important finding in the heart failure pandemic era arriving in the near future. The subsequent DAPAHF study (56) showed that SGLT2 inhibitors reduce cardiovascular death and heart failure hospitalizations in heart failure patients with reduced left ventricular systolic function, with or without diabetes mellitus. The mechanism of this beneficial effect of SGLT2 inhibitors is still unclear, and further studies are needed to understand the mechanism of this cardiovascular effect.

\section{Smoking}

Smoking is also a major risk for CVD. Smoking increases the risk of mortality from CVD by 2.07fold (57). Our study also showed that smoking would increase unstable plaque in the carotid arteries (58). Passive smoking, even in the absence of smoking, has also been shown to increase the risk of atherosclerosis, stroke, and all-cause mortality. A meta-analysis shows that smoking increases all-cause mortality by 1.18 times and CVD by 1.23 times (59). In addition, one-third of coronary artery disease deaths were associated with smoking or passive smoking (32). In Japan, awarenessraising efforts have been vigorous and smoking rates have decreased significantly (Figure S3, https://www. globalhealthmedicine.com/site/supplementaldata. $\mathrm{html}$ ? ID=27) (60). Because smoking is also a risk factor for the development of many malignancies, additional anti-smoking educational activities are needed.

\section{Physical inactivity}

Lack of exercise habits has also been shown to be a risk factor for CVD (32). The development of urban lifestyles, including sedentary work indoors, has reduced the amount of time people spend on exercise and physical activity. An important theme in preventive medicine is the setting of appropriate exercise habits tailored to each person's lifestyle.

\section{Japan's health examination system and comparison with other countries}

We have described that CVD are important in Japan's medical care in various ways, and that early detection and treatment of lifestyle-related diseases underlying CVD can prevent development of CVD. Japan's health checkup system would be useful for early detection of 
lifestyle-related diseases and prevention of future CVD.

The health examination system in Japan has three main components: health examination of workers, health examination of community residents, and health examination of students. The first health examination of workers was made mandatory by employers under the Labor Standards Law, which was enacted in 1947. At that time, the main purpose was the early detection of tuberculosis, but after that, with a decrease in the number of tuberculosis infections. The Occupational Safety and Health Law was enacted in 1972, and blood pressure measurement was added for the purpose of early detection and treatment of hypertension. Since then, health checkups have been launched for the purpose of health management, and these have become the current regular health checkups. Health checkups for local residents are carried out by health centers under the Community Health Law. Students are required to undergo medical examinations by June 30 of each school year under the School Health and Safety Act of 1958.

In addition, the system of voluntary physical examinations called "Ningen (Human) dock", which began in 1954, is unique to Japan. This system was initiated for the wealthy, but it has since become more widespread, with approximately three million people undergoing the procedure each year. The physical examinations also include options such as brain and heart checks, and the early detection of CVD is one of the main purposes of the complete physical examinations.

In the United States, health examinations are also conducted under the direction of family physicians and are voluntary, as in Japan, but the content of the examinations is not as uniform as in Japan. In the U.K., free medical examinations are provided by the national health insurance system through registered family physicians, but the content of these examinations is not as comprehensive as in Japan.

In this regard, it is of academic interest to know the extent to which the specific health checkups (metabolic syndrome checkups) that have been carried out in Japan since 2008, as well as the Ningen dock for 3 million people who voluntarily undergo them at their own expense, contribute to the early detection and prevention of lifestyle-related diseases and CVD.

\section{Utilizing physical examination data and health checkup data for clinical research}

A large amount of data on physical examinations are valuable real-world data that can be utilized for clinical research. In the following, we would like to introduce our research activities using these real-world data.

Physical examination data analyses have already shown various findings. These below are several examples of our research in collaboration with the Department of Cardiovascular Medicine and the
Preventive Medicine Center, the University of Tokyo Hospital. The definition of hypertension differs among the United States and Europe and Japan, which is controversial even today. The association between carotid intima-media thickening, a good predictor of future $\mathrm{CVD}$, and the new BP categories according to updated ACC/AHA guidelines was examined in those who underwent physical examinations at the Preventive Medicine Center. The results showed that, in stage 1 hypertension, which is defined as systolic blood pressure of 130-139 mmHg or diastolic blood pressure of $80-89 \mathrm{mmHg}$, early phase atherosclerotic plaques were more likely to develop than in the normotensive group (61). Similar results were obtained for CAVI (cardio-ankle vascular index), a measure of arterial stiffness, in males (62). These findings suggest that stage 1 hypertension according to the updated ACC/ AHA blood pressure classification is significantly associated with atherosclerotic change in adults.

Another example is about body weight change, which is one of the most important parameters in preventive medicine. We reported that body composition data showed that body fat weight change accounts for about $70 \%$ of the body weight change in adulthood (63), and that this should be considered to be primarily a change in fat weight, both during weight gain and during weight loss. It was also reported that changes in body weight over time are strongly associated with changes in blood pressure (64) and lipid profiles (65), emphasizing the importance of weight control in management of lifestyle-related diseases.

We want to mention metabolically healthy obesity, which is defined as "obesity (BMI $\geq 25 \mathrm{~kg} / \mathrm{m}^{2}$ ) but not meeting the diagnostic criteria for metabolic syndrome in Japan" compared to the non-obese group. It has been shown that carotid intima-media thickness progresses in the metabolically healthy obesity group (66). On the other hand, the risk of atherosclerosis increases from the stage when abdominal circumference is smaller than the criteria for abdominal circumference $(85 \mathrm{~cm}$ or more for men and $90 \mathrm{~cm}$ or more for women), which is included in the diagnostic criteria for metabolic syndrome in Japan (67), suggesting the optimal abdominal circumference cutoff for predicting development of cardiovascular events remains controversial. Smoking was shown to be an independent risk factor for carotid artery highrisk plaque formation (58), suggesting that smoking is significantly related to the early-phase pathogenic process of acute coronary syndromes and cerebral infarction.

With regard to health screening, we are collaborating with the Department of Clinical Epidemiology on a study using the JMDC Claims Database, which mainly collects data on health checkups and insurance claims data. It has already shown that the Cardiovascular Health Metrics, an indicator of risk for CVD, are correlated between couples (68), and that a weight gain 
of $10 \mathrm{~kg}$ or more from age 20 years, even in the absence of obesity, is associated with an increased risk of future cardiovascular events (69). Additionally, we have also reported the importance of modifiable risk factors for the prevention of CVD in young adults (70-72), and the association of the blood pressure classification according to the $2017 \mathrm{ACC} / \mathrm{AHA}$ guideline with the incidence of CVD (43). These real-world data will have great potential for further clinical investigation.

As the importance of preventive cardiology increases in the future, we should analyze the real-world data from health checkups in Japan in detail and disseminate these results to clinical practice, which would promote preventive medicine and public health.

\section{Conclusion}

By reviewing the changes in the major causes of death in Japan, we believe that CVD will become even more important in Japan in the future, and that they will not be overlooked in terms of shortening healthy life expectancy and increasing medical costs. Most importantly, CVD can be prevented by intervening in the modifiable lifestyle and lifestyle-related diseases that predispose people to CVD. In light of these points, Japan's universal health insurance system and extensive health checkup system, which cover almost all of its citizens, would play an important role. We need to disseminate knowledge gained by use of data from the universal health insurance system, and the health checkup system conducted on the Japanese people, which will contribute to the development of preventive cardiology.

\section{Funding: None.}

Conflict of Interest: The authors have no conflicts of interest to disclose.

\section{References}

1. Cabinet Office. Moonshot Research and Development Project. https://www8.cao.go.jp/cstp/moonshot/index.html (accessed May 2, 2021). (in Japanese)

2. Ministry of Health, Labour and Welfare. Vital Statistics. https://www.mhlw.go.jp/toukei/saikin/hw/jinkou/geppo/ nengai18/dl/gaikyou30.pdf (accessed May 2, 2021). (in Japanese)

3. National Center for Health Statistics. Death and Mortality. https://www.cdc.gov/nchs/fastats/deaths.htm (accessed May 2, 2021).

4. Tokyo Metropolitan Institute of Public Health. 100 years of tuberculosis in demographic statistics. http://www. tokyo-eiken.go.jp/sage/sage2003/ (accessed August 14, 2021). (in Japanese)

5. Yoshihiro Kokubo. Trends in Stroke in Japan and abroad. http://www.jacd.info/library/jjcdp/review/52-3_01_\%20 kokubo.pdf(accessed May 2, 2021). (in Japanese)

6. Ministry of Health, Labour and Welfare. Changes in
Health Policy in Japan. https://www.mhlw.go.jp/wp/ hakusyo/kousei/14/dl/1-01.pdf (accessed May 2, 2021). (in Japanese)

7. The Ministry of Health, Labour and Welfare. About specific health screening and specific health guidance. https://www.mhlw.go.jp/stf/seisakunitsuite/ bunya/0000161103.html (accessed May 2, 2021). (in Japanese)

8. Okura Y, Ramadan MM, Ohno Y, Mitsuma W, Tanaka K, Ito M, Suzuki K, Tanabe N, Kodama M, Aizawa Y. Impending epidemic: future projection of heart failure in Japan to the year 2055. Circ J. 2008; 72:489-491.

9. Cabinet Office. International Trends in Population Aging. https://www8.cao.go.jp/kourei/whitepaper/w-2018/html/ zenbun/s1_1_2.html (accessed May 2, 2021). (in Japanese)

10. Ministry of Internal Affairs and Communications. Population of the Elderly, Bureau of Statistics. https:// www.stat.go.jp/data/topics/topi1211.html (accessed May 2, 2021). (in Japanese)

11. Kaneko H, Itoh H, Yotsumoto H, Kiriyama H, Kamon T, Fujiu K, Morita K, Michihata N, Jo T, Morita H, Yasunaga H, Komuro I. Characteristics and outcomes of superelderly patients (aged $\geq 90$ years) hospitalized for heart failure - analysis of a nationwide inpatient database. Circ Rep. 2020; 2:393-399.

12. Ministry of Health, Labour and Welfare. Healthy life expectancy. https://www.mhlw.go.jp/bunya/kenkou/dl/ chiiki-gyousei_03_02.pdf(accessed May 2, 2021). (in Japanese)

13. Gedela M, Khan M, Jonsson O. Heart failure. S D Med. 2015; 68:403-5, 407-9.

14. Rodriguez-Manero M,Grigorian-Shamagian L, Rabago G, Abou-Jokh C, Alvarez B, Brion M, Gonzalez-Juanatey JR. Innovative strategies in heart failure: present and future. Arch Med Res. 2018; 49:558-567.

15. Van Nuys KE, Xie Z, Tysinger B, Hlatky MA, Goldman DP. Innovation in heart failure treatment: life expectancy, disability, and health disparities. JACC Heart Fail. 2018; 6:401-409.

16. Ministry of Health, Labour and Welfare (MHLW). Breaking down the factors of health care cost growth. https://www.mhlw.go.jp/file/05-Shingikai-12404000Hokenkyoku-Iryouka/0000137953.pdf (accessed May 2, 2021). (in Japanese)

17. Ministry of Health, Labour and Welfare (MHLW). National health care cost status. https://www.mhlw.go.jp/ toukei/saikin/hw/k-iryohi/15/dl/kekka.pdf (accessed May 2, 2021). (in Japanese)

18. Yusuf S, Joseph P, Rangarajan S, et al. Modifiable risk factors, cardiovascular disease, and mortality in 155,722 individuals from 21 high-income, middle-income, and low-income countries (PURE): a prospective cohort study. Lancet. 2020; 395:795-808.

19. Gourgari E, Dabelea D, Rother K. Modifiable risk factors for cardiovascular disease in children with type 1 diabetes: can early intervention prevent future cardiovascular events? Curr Diab Rep. 2017; 17:134.

20. Harris KC, Voss C, Rankin K, Aminzadah B, Gardner $\mathrm{R}$, Mackie AS. Modifiable cardiovascular risk factors in adolescents and adults with congenital heart disease. Congenit Heart Dis. 2018; 13:563-570.

21. Framingham Heart Study. Three genarations of research on heart disease. https://framinghamheartstudy.org (accessed May 2, 2021). (in Japanese)

22. Tsao CW, Vasan RS. Cohort profile: the Framingham 
Heart Study (FHS): overview of milestones in cardiovascular epidemiology. Int J Epidemiol. 2015; 44:1800-1813.

23. Wilson PW, D'Agostino RB, Levy D, Belanger AM, Silbershatz H, Kannel WB. Prediction of coronary heart disease using risk factor categories. Circulation. 1998; 97:1837-1847.

24. Kyushu University Graduate School. The Hisayama Study. http://www.hisayama.med.kyushu-u.ac.jp/about/ index.html (accessed May 2, 2021). (in Japanese)

25. Oishi E, Ohara T, Sakata S, Fukuhara M, Hata J, Yoshida D, Shibata M, Ohtsubo T, Kitazono T, Kiyohara Y, Ninomiya T. Day-to-day blood pressure variability and risk of dementia in a general Japanese elderly population: the Hisayama Study. Circulation. 2017; 136: 516-525.

26. Cardiovascular Trial Database. Hisayama Study. https:// www.ebm-library.jp/circ/trial/doc/c2001102.html (accessed May 2, 2021). (in Japanese)

27. Kudo K, Hata J, Matsumoto K, Shundo Y, Fukuyama $\mathrm{S}$, Inoue $\mathrm{H}$, Kitazono $\mathrm{T}$, Kiyohara $\mathrm{Y}$, Ninomiya $\mathrm{T}$, Nakanishi Y. Association of airflow limitation with carotid atherosclerosis in a Japanese community-the Hisayama study. Circ J. 2017; 81:1846-1853.

28. Cardiovascular Trial Database. Suita Study. https://www. ebm-library.jp/circ/trial/doc/c2001005.html (accessed May 2, 2021). (in Japanese)

29. Hirai H, Asahi K, Yamaguchi S, et al. New risk prediction model of coronary heart disease in participants with and without diabetes: assessments of the Framingham risk and Suita scores in 3-year longitudinal database in a Japanese population. Sci Rep. 2019; 9:2813.

30. National Cerebral and Cardiovascular Research Center. Development of a new risk score to predict coronary artery disease. $h t t p: / / w w w . n c v c . g o . j p / p r / r e l e a s e / 006484$. html (accessed May 2, 2021). (in Japanese)

31. Kagawa Y. Impact of Westernization on the nutrition of Japanese: changes in physique, cancer, longevity and centenarians. Prev Med. 1978; 7:205-217.

32. American College of cardiology. 2019 ACC/AHA guideline on the primary prevention of cardiovascular disease. https://www.acc.org/latest-in-cardiology/tenpoints-to-remember/2019/03/07/16/00/2019-acc-ahaguideline-on-primary-prevention-gl-prevention (accessed May 2, 2021).

33. Ministry of Health, Labour and Welfare. Diagnostic criteria for metabolic syndrome. https://www.mhlw.go.jp/ bunya/kenkou/seikatsu/pdf/ikk-j-07.pdf (accessed May 2, 2021). (in Japanese)

34. Stefan N, Haring HU, Hu FB, Schulze MB. Metabolically healthy obesity: epidemiology, mechanisms, and clinical implications. Lancet Diabetes Ecdocrinol. 2013; 1:152162.

35. Mongraw-Chaffin M, Foster MC, Anderson CAM, Burke GL, Haq N, Kalyani RR, Ouyang P, Sibley CT, Tracy R, Woodward M, Vaidya D. Metabolically healthy obesity, transition to metabolic syndrome, and cardiovascular risk. J Am Coll Cardiol. 2018; 71:1857-1865.

36. Social Facts and Figures. Salt intake of Japanese people. http://honkawa2.sakura.ne.jp/2173.html (accessed May 2, 2021). (in Japanese)

37. Whelton PK, Carey RM, Aronow WS, et al. 2017 ACC/ AHA/AAPA/ABC/ACPM/AGS/APhA/ASH/ASPC/ NMA/PCNA Guideline for the Prevention, Detection, Evaluation, and Management of High Blood Pressure in Adults: Executive Summary: A Report of the American
College of Cardiology/American Heart Association Task Force on Clinical Practice Guidelines. Circulation. 2018;138:e426-e483.

38. Williams B, Mancia G, Spiering W, et al. 2018 ESC/ESH Guidelines for the management of arterial hypertension. Eur Heart J. 2018; 39:3021-3104.

39. Umemura S, Arima H, Arima $\mathrm{S}$, et al. The Japanese Society of Hypertension Guidelines for the Management of Hypertension (JSH 2019). Hypertens Res. 2019; 42:1235-1481.

40. SPRINT Research Group, Wright JT Jr, Williamson JD, et al. A randomized trial of intensive versus standard bloodpressure control. N Engl J Med. 2015; 373:2103-2116.

41. Yano Y, Reis JP, Colangelo LA, Shimbo D, Viera AJ, Allen NB, Gidding SS, Bress AP, Greenland P, Muntner P, Lloyd-Jones DM. Association of blood pressure classification in young adults using the 2017 American College of Cardiology/American Heart Association Blood Pressure Guideline With Cardiovascular Events Later in Life. JAMA. 2018; 320:1774-1782.

42. Son JS, Choi S, Kim K, Kim SM, Choi D, Lee G, Jeong SM, Park SY, Kim YY, Yun JM, Park SM. Association of blood pressure classification in Korean young adults according to the 2017 American College of Cardiology/ American Heart Association Guidelines With Subsequent Cardiovascular Disease Events. JAMA. 2018; 320:17831792.

43. Kaneko H, Yano Y, Itoh H, Morita K, Kiriyama H, Kamon T, Fujiu K, Michihata N, Jo T, Takeda N, Morita H, Node K, Carey RM, Lima JAC, Oparil S, Yasunaga H, Komuro I. Association of Blood Pressure Classification Using the 2017 American College of Cardiology/American Heart Association Blood Pressure Guideline With Risk of Heart Failure and Atrial Fibrillation. Circulation. 2021; 143:2244-2253.

44. Sata M, Okamura T. Changes in serum cholesterol levels and dyslipidemia over time in Japan. http://www.jacd.info/ library/jjcdp/review/53-3_02_sata.pdf (accessed May 2, 2021). (in Japanese)

45. Ministry of Health, Labour and Welfare. Status of lifestyle-related diseases. https://www.mhlw.go.jp/ houdou/2008/04/dl/h0430-2k.pdf (accessed May 2, 2021). (in Japanese)

46. Ballantyne CM. Low-density lipoproteins and risk for coronary artery disease. Am J Cardiol. 1998; 82:3Q-12Q.

47. Action to Control Cardiovascular Risk in Diabetes Study Group, Gerstein HC, Miller ME, Byington RP, Goff DC Jr, Bigger JT, Buse JB, Cushman WC, Genuth S, IsmailBeigi F, Grimm RH Jr, Probstfield JL, Simons-Morton DG, Friedewald WT. Effects of intensive glucose lowering in type 2 diabetes. N Engl J Med. 2008; 358:2545-2559.

48. ADVANCE Collaborative Group, Patel A, MacMahon $\mathrm{S}$, et al. Intensive blood glucose control and vascular outcomes in patients with type 2 diabetes. N Engl J Med. 2008; 358:2560-2572.

49. Duckworth W, Abraira C, Moritz T, et al. Glucose control and vascular complications in veterans with type 2 diabetes. N Engl J Med. 2009; 360:129-139.

50. Scirica BM, Bhatt DL, Braunwald E, et al. Saxagliptin and cardiovascular outcomes in patients with type 2 diabetes mellitus. N Engl J Med. 2013; 369:1317-1326.

51. White WB, Cannon CP, Heller SR, Nissen SE, Bergenstal RM, Bakris GL, Perez AT, Fleck PR, Mehta CR, Kupfer S, Wilson C, Cushman WC, Zannad F; EXAMINE Investigators. Alogliptin after acute coronary syndrome 
in patients with type 2 diabetes. N Engl J Med. 2013; 369:1327-1335.

52. Green JB, Bethel MA, Armstrong PW, et al. Effect of sitagliptin on cardiovascular outcomes in type 2 diabetes. N Engl J Med. 2015; 373:232-242.

53. Zinman B, Wanner C, Lachin JM, Fitchett D, Bluhmki E, Hantel S, Mattheus M, Devins T, Johansen OE, Woerle HJ, Broedl UC, Inzucchi SE; EMPA-REG OUTCOME Investigators. Empagliflozin, cardiovascular outcomes, and mortality in type 2 diabetes. N Engl J Med. 2015; 373:2117-2128.

54. Neal B, Perkovic V, Mahaffey KW, de Zeeuw D, Fulcher G, Erondu N, Shaw W, Law G, Desai M, Matthews DR; CANVAS Program Collaborative Group. Canagliflozin and cardiovascular and renal events in type 2 diabetes. $\mathrm{N}$ Engl J Med. 2017; 377:644-657.

55. Zinman B, Lachin JM, Inzucchi SE. Empagliflozin, cardiovascular outcomes, and mortality in type 2 diabetes. N Engl J Med. 2016; 374:1094.

56. McMurray JJV, Solomon SD, Inzucchi SE, et al. Dapagliflozin in patients with heart failure and reduced ejection fraction. N Engl J Med. 2019; 381:1995-2008.

57. Mons U, Muezzinler A, Gellert C, et al. Impact of smoking and smoking cessation on cardiovascular events and mortality among older adults: meta-analysis of individual participant data from prospective cohort studies of the CHANCES consortium. BMJ. 2015; 350:h1551.

58. Kiriyama $H$, Kaneko $H$, Itoh $H$, Yoshida $Y$, Nakanishi K, Mizuno Y, Daimon M, Morita H, Yamamichi N, Komuro I. Effect of cigarette smoking on carotid artery atherosclerosis: a community-based cohort study. Heart Vessels. 2020; 35:22-29.

59. Lv X, Sun J, Bi Y, Xu M, Lu J, Zhao L, Xu Y. Risk of allcause mortality and cardiovascular disease associated with secondhand smoke exposure: A systematic review and meta-analysis. Int J Cardiol. 2015; 199:106-115.

60. Ministry of Health, Labour and Welfare. Latest Tobacco Information. http://www.health-net.or.jp/tobacco/product/ pd090000.html (accessed May 2, 2021). (in Japanese)

61. Itoh H, Kaneko H, Kiriyama H, Yoshida Y, Nakanishi K, Mizuno Y, Daimon M, Morita H, Yatomi Y, Komuro I. Relation between the Updated Blood Pressure Classification according to the American College of Cardiology/American Heart Association Guidelines and Carotid Intima-Media Thickness. Am J Cardiol. 2019; 124:396-401.

62. Kamon $\mathrm{T}$, Kaneko $\mathrm{H}$, Itoh $\mathrm{H}$, Kiriyama H, Mizuno $\mathrm{Y}$, Morita H, Yamamichi N, Komuro I. Gender-specific association between the blood pressure category according to the updated ACC/AHA guidelines for hypertension and cardio-ankle vascular index: a community-based cohort study. J Cardiol. 2020; 75:578-582.

63. Itoh H, Kaneko H, Kiriyama H, Kamon T, Mizuno Y, Morita H, Yamamichi N, Komuro I. Association between changes in body weight and fat weight in middle age general population. Int Heart J. 2020; 61:15-20.

64. Itoh H, Kaneko H, Kiriyama H, Nakanishi K, Mizuno Y, Daimon M, Morita H, Yamamichi N, Komuro I. Effect of body weight change on blood pressure in a Japanese general population with a body mass index $\geq 22 \mathrm{~kg} / \mathrm{m}^{2}$. Int Heart J. 2019; 60:1381-1386.

65. Kiriyama H, Kaneko H, Itoh H, Kamon T, Mizuno Y, Fujiu K, Morita H, Yamamichi N, Komuro I. Association between changes in body weight and lipid profile in the general population: a community-based cohort study. Eur Heart J Qual Care Clin Outcomes. 2021; 7:109-110.

66. Itoh H, Kaneko H, Kiriyama H, Yoshida Y, Nakanishi K, Mizuno Y, Daimon M, Morita H, Yatomi Y, Yamamichi N, Komuro I. Effect of metabolically healthy obesity on the development of carotid plaque in the general population: a community-based cohort study. J Atheroscler Thromb. 2020; 27:155-163

67. Kamon T, Kaneko H, Itoh H, Kiriyama H, Mizuno Y, Morita H, Yamamichi N, Komuro I. Association between waist circumference and carotid intima-media thickness in the general population. Int Heart J. 2020; 61:103-108.

68. Kaneko H, Itoh H, Yotsumoto H, Kiriyama H, Kamon T, Fujiu K, Morita K, Kashiwabara K, Michihata N, Jo T, Morita H, Yasunaga H, and Komuro I. Cardiovascular health metrics of 87,160 couples: analysis of a nationwide epidemiological database. J Atheroscler Thromb. 2020. doi: 10.5551/jat.55939.

69. Kaneko H, Itoh H, Yotsumoto H, Kiriyama H, Kamon T, Fujiu K, Morita K, Michihata N, Jo T, Morita H, Yasunaga H, Komuro I. Association of body weight gain with subsequent cardiovascular event in non-obese general population without overt cardiovascular disease. Atherosclerosis. 2020; 308:39-44.

70. Kaneko H, Itoh H, Kamon T, Fujiu K, Morita K, Michihata N, Jo T, Morita H, Yasunaga H, Komuro I. Association of cardiovascular health metrics with subsequent cardiovascular disease in young adults. J Am Coll Cardiol. 2020; 76:2414-2416.

71. Kaneko H, Itoh H, Kiriyama H, Kamon T, Fujiu K, Morita K, Michihata N, Jo T, Takeda N, Morita H, Yasunaga H, Komuro I. Lipid profile and subsequent cardiovascular disease among young adults aged $<50$ years. Am J Cardiol. 2021; 142:59-65.

72. Kaneko H, Itoh H, Kiriyama H, Kamon T, Fujiu K, Morita K, Michihata N, Jo T, Takeda N, Morita H, Yasunaga H, Komuro I. Fasting plasma glucose and subsequent cardiovascular disease among young adults: Analysis of a nationwide epidemiological database. Atherosclerosis. 2021; 319:35-41.

Received September 1, 2020; Revised August 3, 2021; Accepted August 10, 2021.

Released online in J-STAGE as advance publication August 23, 2021 .

*Address correspondence to:

Hidehiro Kaneko, Department of Cardiovascular Medicine, The University of Tokyo, Tokyo 113-8655, Japan.

E-mail: kanekohidehiro@gmail.com 